\title{
Freestanding Surface Disordered NiCu Solid Solution as Ultrastable High Current Density Hydrogen Evolution Reaction Electrode
}

Xiaoxiang Zhang, ${ }^{\dagger}, \ddagger$ Jie Wang, ${ }^{\dagger},+$ Junying Wang, ${ }^{\dagger}$ Junzhong Wang, ${ }^{\dagger}, \ddagger$ Congwei Wang $*$,

$\dagger$ and Chunxiang $L u^{\dagger, \ddagger} \S$

${ }^{\dagger}$ CAS Key Laboratory of Carbon Materials, Institute of Coal Chemistry, Chinese Academy of Sciences, Taiyuan 030001, China

*Center of Materials Science and Optoelectronics Engineering, University of Chinese Academy of Sciences, Beijing 100049, China

$\S$ National Engineering Laboratory for Carbon Fiber Technology, Institute of Coal Chemistry, Chinese Academy of Sciences, Taiyuan 030001, China

*The corresponding author.

E-mail: wangcongwei@sxicc.ac.cn 


\section{Synthesis of electrocatalysts}

The $\mathrm{Ni}_{1-x} \mathrm{Cu}_{x} \mathrm{DSS}$ was prepared by a one-step hydrothermal method. In a typical experiment, $\mathrm{Ni}\left(\mathrm{CH}_{3} \mathrm{COO}\right)_{2} \cdot 4 \mathrm{H}_{2} \mathrm{O}$ and $\mathrm{Cu}\left(\mathrm{CH}_{3} \mathrm{COO}\right)_{2} \cdot \mathrm{H}_{2} \mathrm{O}$ (molar ratio of 1-x:x, $x=0$, $0.03,0.05,0.1,1)$ were dispersed in the mix solution $(0.2 \mathrm{M}$ metal ion) consisting of $20 \mathrm{~mL}$ deionized water, $10 \mathrm{~mL}$ ammonia solution $(25 \mathrm{wt} . \%)$ and $3 \mathrm{~mL}$ hydrazine hydrate. In particular, when the $x=0$ and $x=1$, the obtained samples were denoted as 'pure $\mathrm{Ni}$ ' and 'pure $\mathrm{Cu}$ ', respectively. The precursor solution was transferred to a Teflon-lined autoclave $(50 \mathrm{~mL})$, and then kept at $160{ }^{\circ} \mathrm{C}$ for $2 \mathrm{~h}$. After cooling to room temperature, the $\mathrm{Ni}_{1-x} \mathrm{Cu}_{x} \mathrm{DSS}$ will float on the surface of the PTFE liner. The sample, about 130 milligrams, was taken out and sandwiched between two clean and flat glass plates weighing about 300 grams and stand for 5 minutes. The obtained sheet-like sample was then washed with deionized water and absolute ethanol several times, and dried in a vacuum oven at $60{ }^{\circ} \mathrm{C}$ for $6 \mathrm{~h}$. The dried sample was cut into small pieces and used as electrodes directly. The unit mass of the obtained electrode is about $20 \mathrm{mg} \mathrm{cm}^{-2}$. For comparison, the $\mathrm{Ni}_{0.95} \mathrm{Cu}_{0.05}$ was synthesized by the same method without the addition of ammonia solution.

The NiFe LDH was synthesized with a modified reported method. In general, 0.5 mmol Fe( $\left(\mathrm{NO}_{3}\right)_{3} \cdot 9 \mathrm{H}_{2} \mathrm{O}, 0.5 \mathrm{mmol} \mathrm{Ni}\left(\mathrm{NO}_{3}\right)_{2} \cdot 6 \mathrm{H}_{2} \mathrm{O}, 3 \mathrm{mmol}$ urea, and $7.5 \mathrm{mmol} \mathrm{NH} 4 \mathrm{~F}$ were dispersed in $30 \mathrm{~mL}$ deionized water. The obtained precursor solution was transferred to a Teflon-lined autoclave $(50 \mathrm{~mL})$, and a clean $2.5 \mathrm{~cm} \times 3 \mathrm{~cm} \mathrm{Ni}$ foam was put into the autoclave, then kept at $120^{\circ} \mathrm{C}$ for $6 \mathrm{~h}$. After cooling to room temperature, the obtained $\mathrm{NiFe} \mathrm{LDH}$ was rinsed with deionized water several times and dried in a vacuum oven at $60^{\circ} \mathrm{C}$ for $6 \mathrm{~h}$. 
To prepare working electrode for commercial $\mathrm{Ni}$ nanoparticle, $10 \mathrm{mg} \mathrm{Ni}$ nanoparticle and $1 \mathrm{ml}$ absolute ethanol were mixed with $20 \mu \mathrm{l} 5 \mathrm{wt}$. \% Nafion solution and keep under sonication for $10 \mathrm{~min}$ to form a homogeneous ink. Then, $100 \mu \mathrm{l}$ catalyst suspension was drop-casted on a $1 \times 1 \mathrm{~cm}$ carbon paper (mass loading $1 \mathrm{mg} \mathrm{cm}^{-2}$ ).

\section{Characterization Methods}

By using a field emission scanning electron microscopy (SEM, JSM-7001F), we investigated the surface morphologies of the electrocatalysts. A transmission electron microscopy (JEM-2100F) was used to conduct the energy dispersive X-ray spectra (EDS) with accelerating voltage of $200 \mathrm{kV}$ and selected area electron diffraction (SAED) analysis. It is noted that to obtain the whole SAED pattern, with careful operation and fewer exposure time, no protective pin/bar was used to black the electron beam. X-ray diffraction (XRD) patterns were collected on a German Bruker D8 ADVANCE with $\mathrm{Cu}$ K $\alpha$ radiation $\left(\lambda=1.5406 \AA\right.$ ) in the range of 5 to $85^{\circ}$. X-ray photoelectron spectroscopy (XPS) data was collected on an AXIS Ultra DLD spectrometer using Al Ka source (1486.6 eV). ICP results were taken by Thermo iCAP6300.

\section{Electrochemical measurements}

All electrochemical characterizations were carried out via a CHI660E electrochemical workstation in a three-electrode system at room temperature, using a Ti sheet as the counter electrode and $\mathrm{Hg} / \mathrm{HgO}$ as the reference electrode, and $1 \mathrm{M} \mathrm{KOH}$ aqueous solution was used as electrolyte. After being cut into pieces with an area of $0.5 \mathrm{~cm}^{2}$, half of the sample was fixed to clamp using hydrophobic silicone glue and the rest half 
sample was used as the working electrodes directly. All the potentials in this work were calibrated relative to the reversible hydrogen electrode (RHE) using

$$
E(\mathrm{RHE})=E(\mathrm{Hg} / \mathrm{HgO})+0.098 \mathrm{~V}+0.0592 \times \mathrm{pH}
$$

(Equation S1)

Linear sweep voltammetry (LSV) with a scan rate of $5 \mathrm{mV} \mathrm{s}^{-1}$ was conducted. Electrochemical impedance spectroscopy (EIS) tests were done in a frequency ranging from $1 \mathrm{~Hz}$ to $100 \mathrm{kHz}$ with $\mathrm{AC}$ amplitude of $10 \mathrm{mV}$. The double-layer capacitance $\left(\mathrm{C}_{\mathrm{dl}}\right)$ was determined by performing cyclic voltammetry (CV) tests with different scanning speeds $\left(10 \mathrm{mv} \mathrm{s}^{-1}, 30 \mathrm{mv} \mathrm{s}^{-1}, 50 \mathrm{mv} \mathrm{s}^{-1}, 70 \mathrm{mv} \mathrm{s}^{-1}, 90 \mathrm{mv} \mathrm{s}^{-1}\right)$ in a specific potential window $(-0.4 \mathrm{~V} \sim-0.5 \mathrm{~V}$ versus $\mathrm{Hg} / \mathrm{HgO})$. The stability was recorded by potential-time curves at a constant current density, and the overall water was performed in a two-electrode system in $1 \mathrm{M} \mathrm{KOH}$ electrolyte with the prepared $\mathrm{NiFe} \mathrm{LDH} / \mathrm{NF}$ and $\mathrm{Ni}_{0.95} \mathrm{Cu}_{0.05} \mathrm{DSS}$ as anode and cathode, respectively.

\section{Theoretical calculations}

All DFT computations were carried out by employing the plane-wave-based method with the Vienna Ab Initio Simulation Package (VASP) and periodic slab model. The electron ion interaction was described with the projector augmented wave (PAW) formula. The electron exchange and correlation energy was used within the generalized gradient approximation (GGA) in the Perdew-Burke-Ernzerhof (PBE) formalism. For structure optimization, the convergence criterion of total energy was set to $1 \times 10^{-5} \mathrm{eV}$, and the atoms were relaxed until the force acting on each atom was less than $0.03 \mathrm{eV}$ $\AA^{-1}$. A plane-wave cutoff energy of $500 \mathrm{eV}$ was used in all calculations. Brillouin-zone was sampled with $3 \times 3 \times 1$ Monkhosrt-Pack grid for slab model calculations. The 
bottom two layers of total four layers were fixed and separated from its neighbors by a sufficiently thick vacuum layer. A $(2 \times 2) \mathrm{Ni}(220)$ surface with one surface atom replaced with a $\mathrm{Cu}$ atom was used as the solid solution system. The Gibbs free energy was calculated by correcting the DFT energy with zero-point energy and entropy via $\Delta G=\Delta E+\triangle Z P E-T \Delta S$, where $\mathrm{E}$ is the DFT total energy, ZPE is the zero-point energy, $\mathrm{T}$ is the environment temperature, and $\mathrm{S}$ is the entropy. For ZPE correction and entropy calculation, the vibrational frequencies were calculated by applying density functional perturbation theory. 


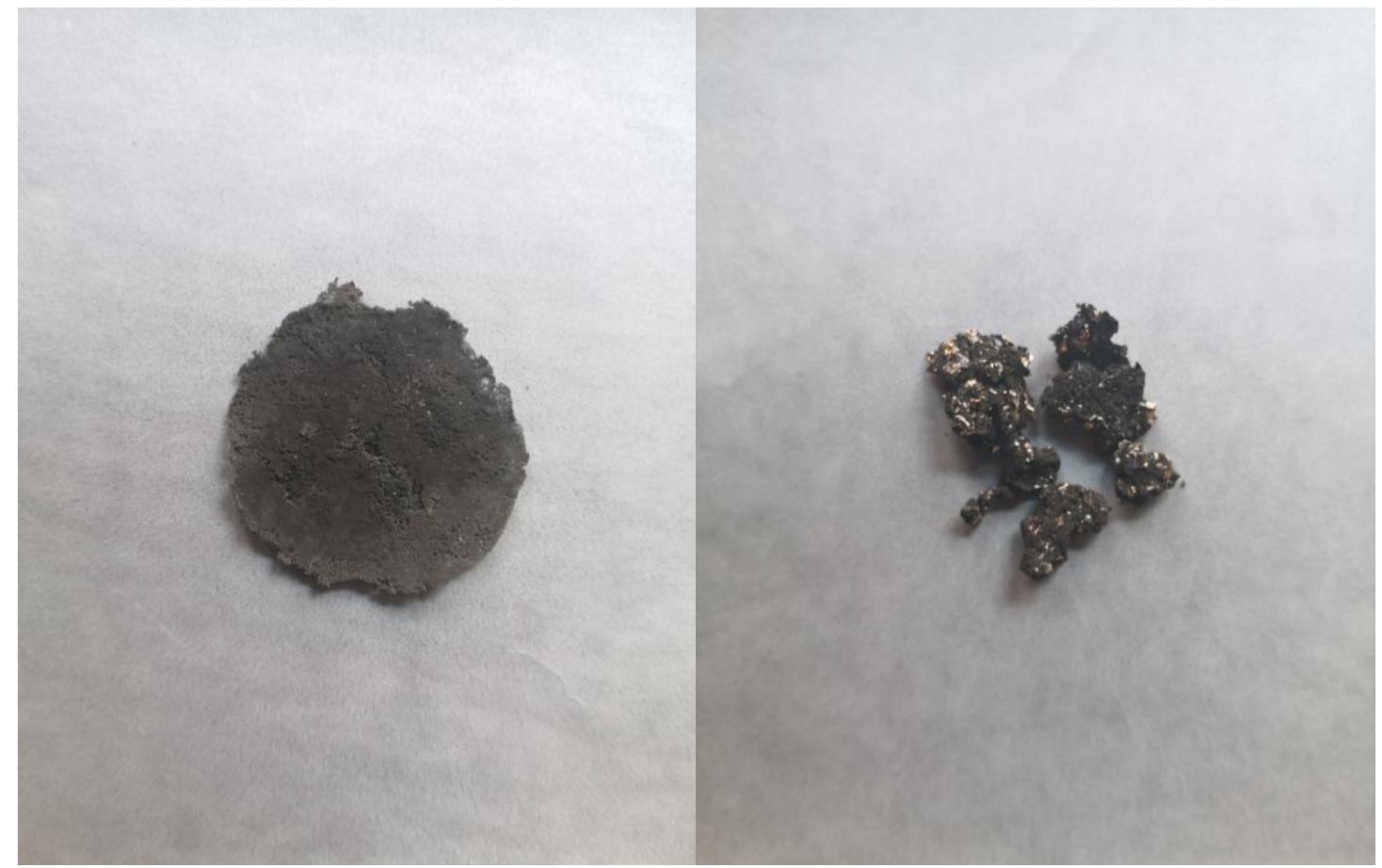

Figure S1. Digital images of $\mathrm{Ni}_{0.95} \mathrm{Cu}_{0.05} \mathrm{DSS}$ (left) and $\mathrm{Ni}_{0.95} \mathrm{Cu}_{0.05}$ (right).

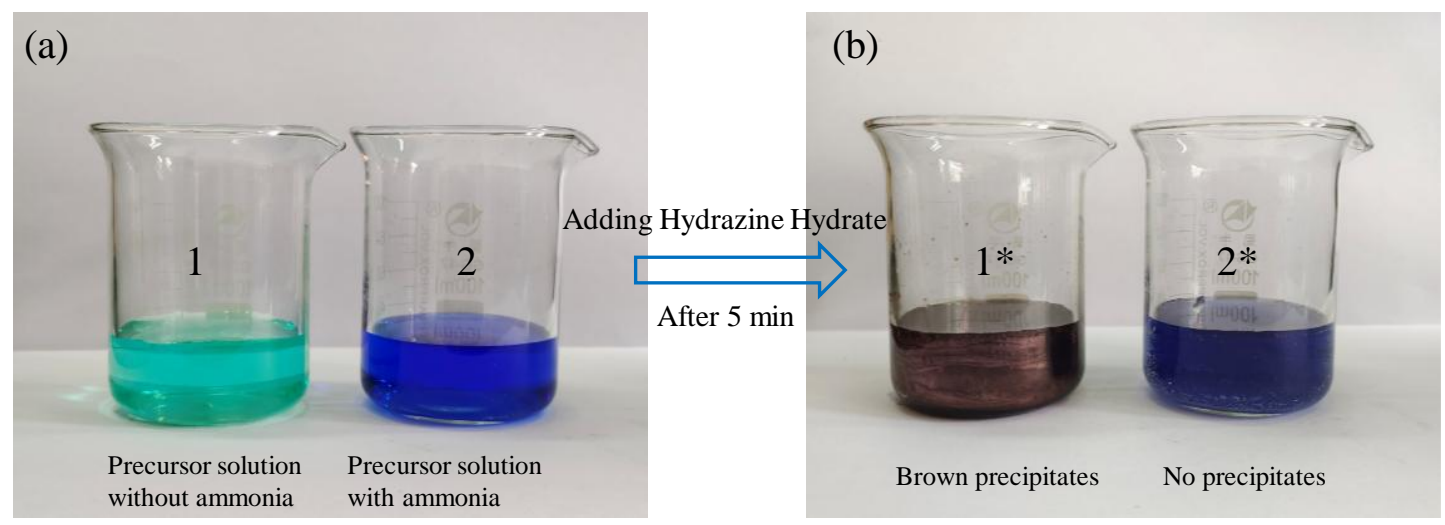

Figure S2. (a) Digital images of initial precursor solution without ammonia (left) and that with ammonia (right). (b) The corresponding digital images after adding hydrazine hydrate and letting it stand for five minutes. 

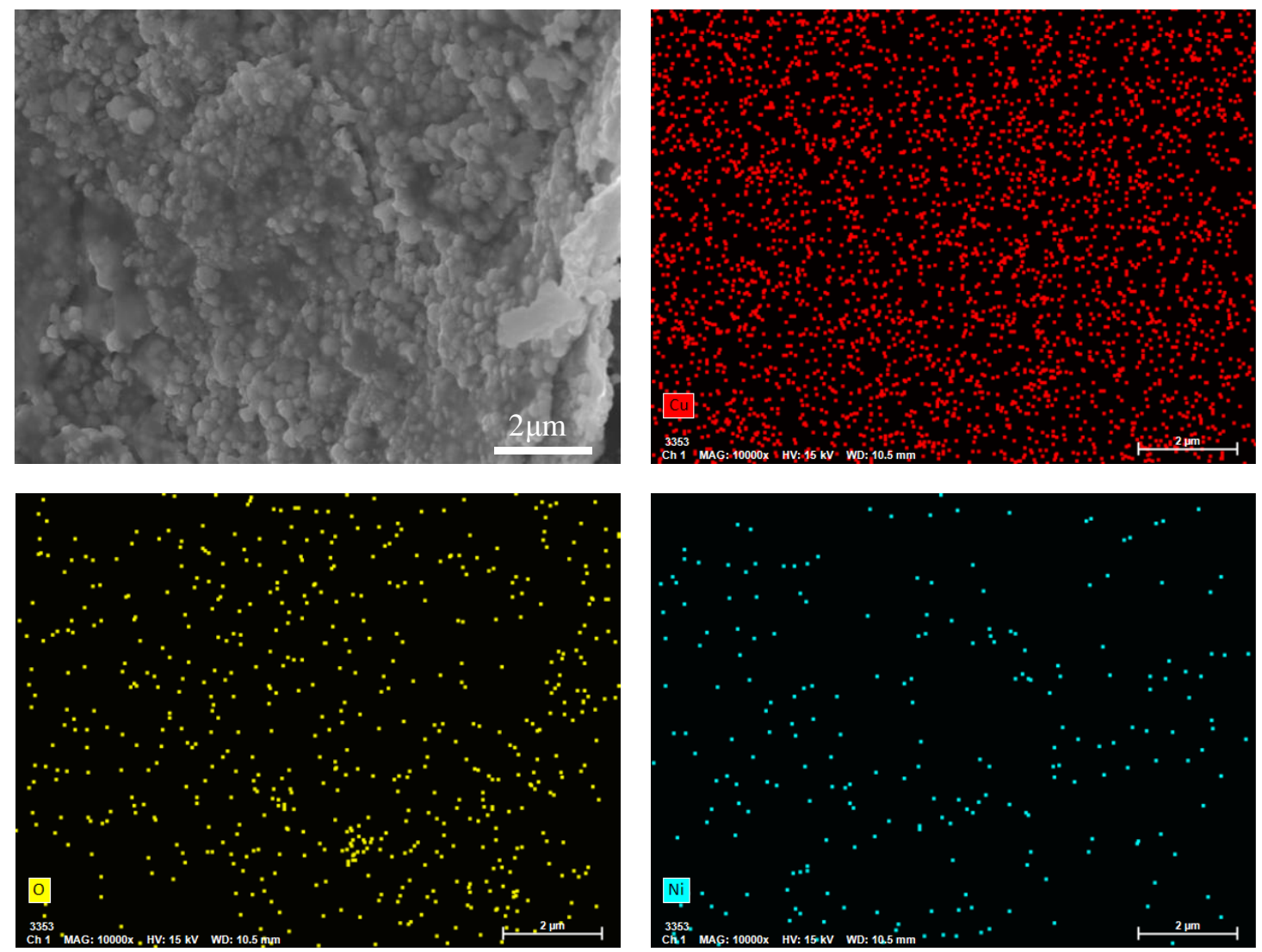

\begin{tabular}{|c|c|c|c|c|}
\hline Element & $\begin{array}{c}\text { atomic } \\
\text { number }\end{array}$ & $\begin{array}{c}\text { Normalized mass } \\
{[\%]}\end{array}$ & $\begin{array}{c}\text { Atomic percent } \\
{[\%]}\end{array}$ & $\begin{array}{c}\text { ads. error } \\
{[\%]} \\
(1 \text { sigma })\end{array}$ \\
\hline $\mathrm{Cu}$ & 29 & $96.29 \%$ & $88.40 \%$ & 3.51 \\
\hline $\mathrm{O}$ & 8 & $2.98 \%$ & $10.88 \%$ & 0.91 \\
\hline $\mathrm{Ni}$ & 28 & $0.72 \%$ & $0.72 \%$ & 0.24 \\
\hline
\end{tabular}

Figure S3. Elemental mapping images of the brown precipitates in Figure S2b. 


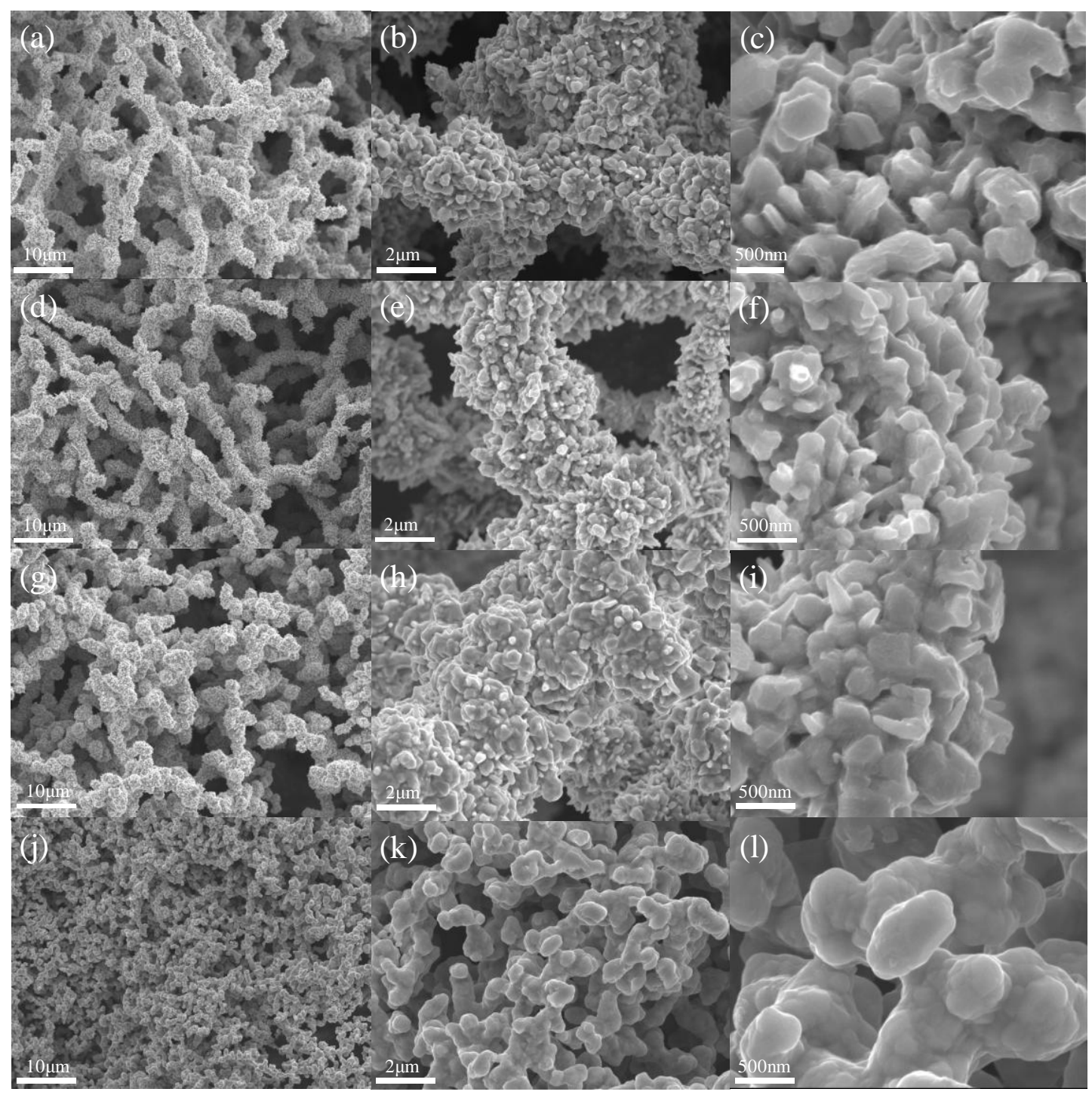

Figure S4. SEM images of the (a-c) pure $\mathrm{Ni}$, (d-f) $\mathrm{Ni}_{0.97} \mathrm{Cu}_{0.03} \mathrm{DSS},(\mathrm{g}-\mathrm{i}) \mathrm{Ni}_{0.9} \mathrm{Cu}_{0.1} \mathrm{DSS}$ and (j-1) pure $\mathrm{Cu}$.
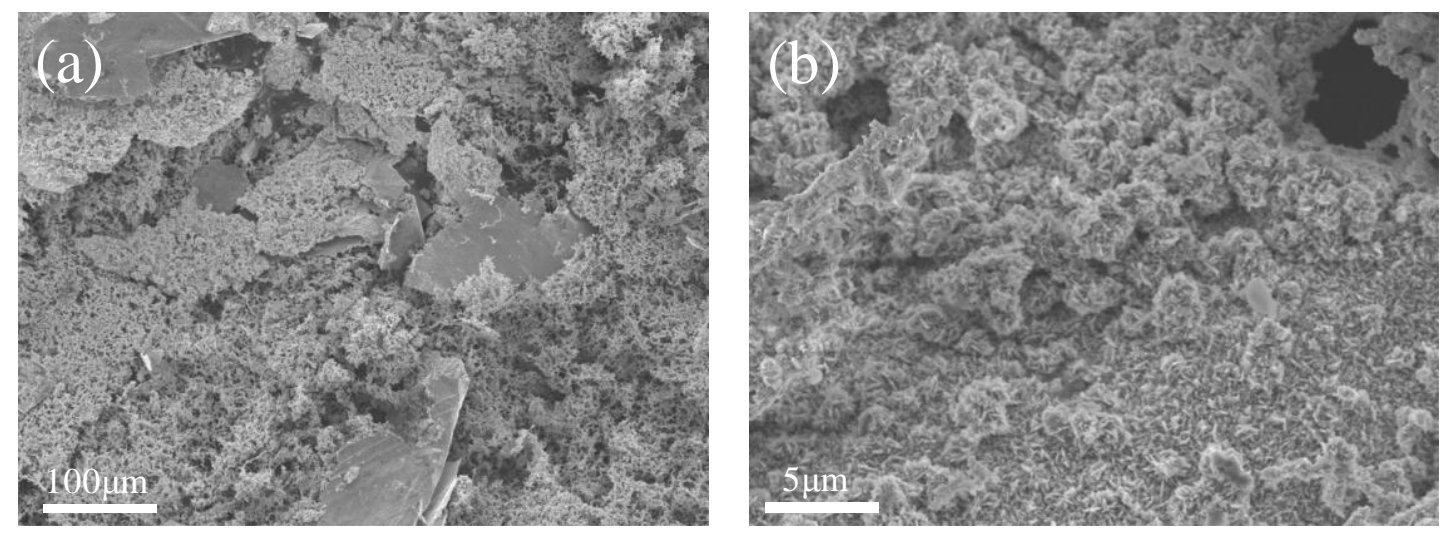

Figure S5. SEM images of the controlling sample $\mathrm{Ni}_{0.95} \mathrm{Cu}_{0.05}$ at different magnifications. 

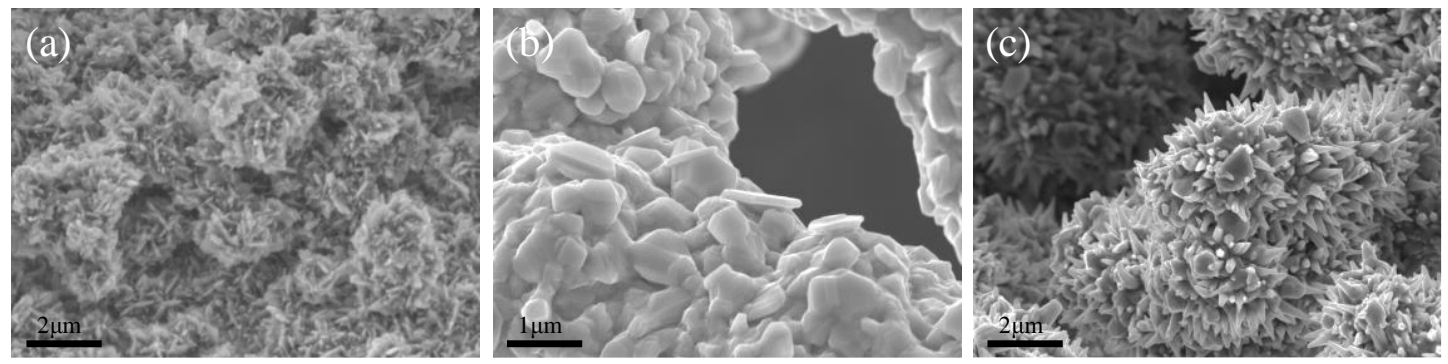

Figure S6. SEM images of (a) $\mathrm{Ni}_{0.95} \mathrm{Cu}_{0.05}$ (No ammonia added), (b) $\mathrm{Ni}_{0.95} \mathrm{Cu}_{0.05} \mathrm{DSS}$ (10 mL ammonia added), (c) $20 \mathrm{~mL}-\mathrm{Ni}_{0.95} \mathrm{Cu}_{0.05} \mathrm{DSS}$ (20 mL ammonia added without changing other experimental conditions.).

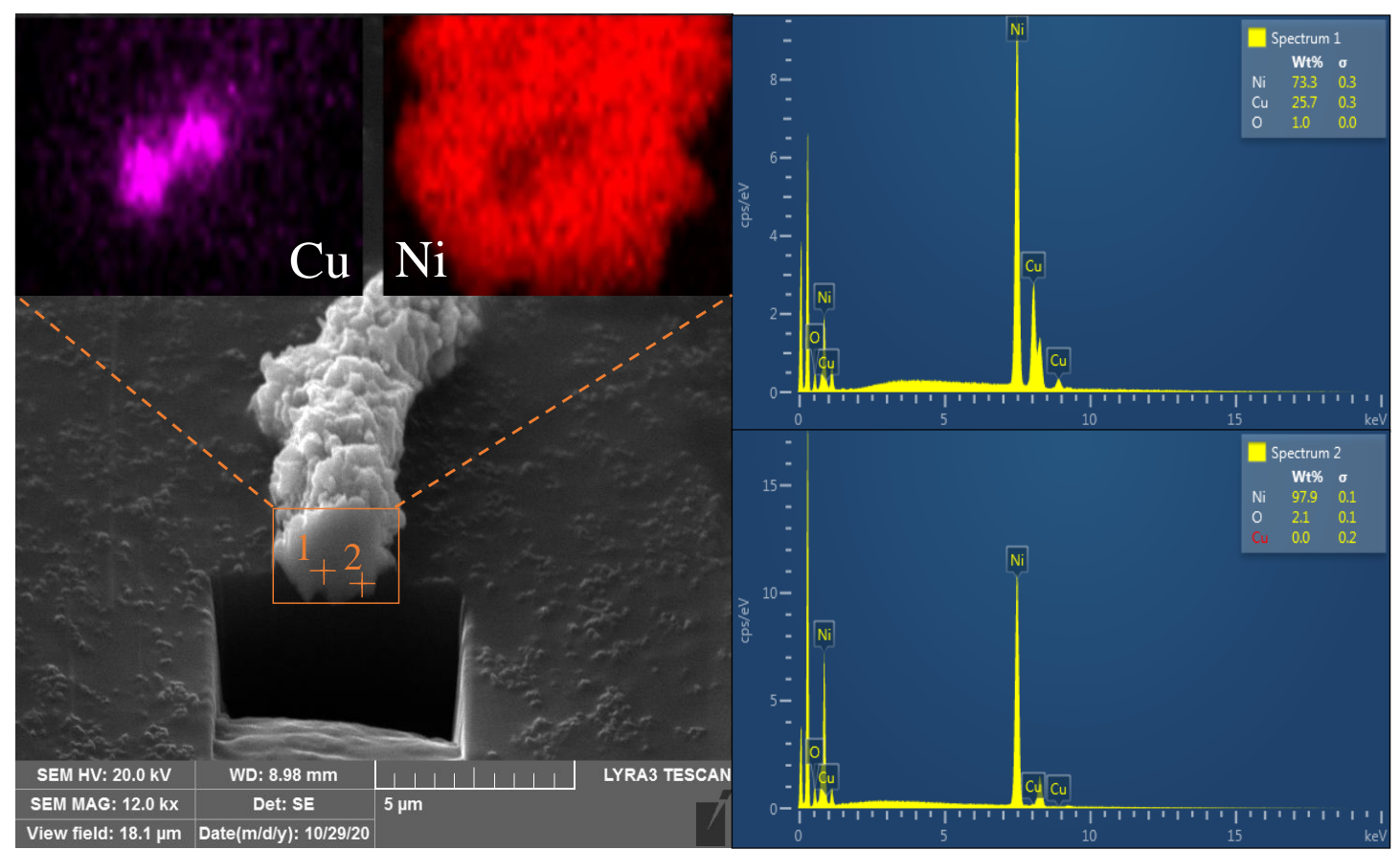

Figure S7. The elemental analyses of the cross section of $\mathrm{Ni}_{0.95} \mathrm{Cu}_{0.05} \mathrm{DSS}$. 


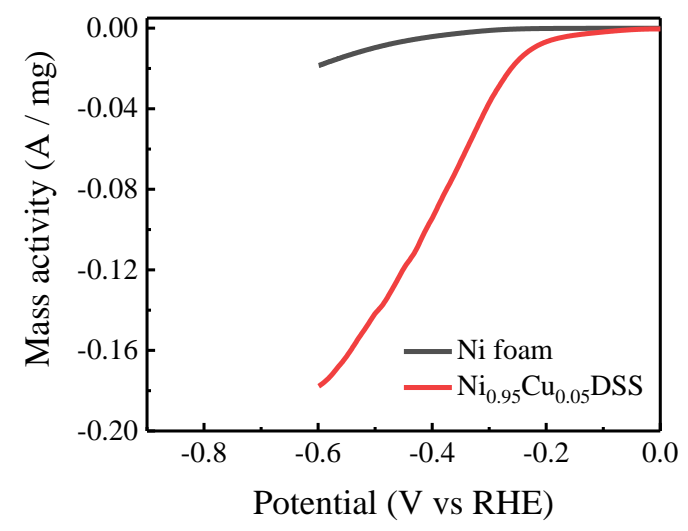

Figure S8. LSV curves of the $\mathrm{Ni}_{0.95} \mathrm{Cu}_{0.05} \mathrm{DSS}$ and commercial $\mathrm{Ni}$ foam as compared in mass activity.
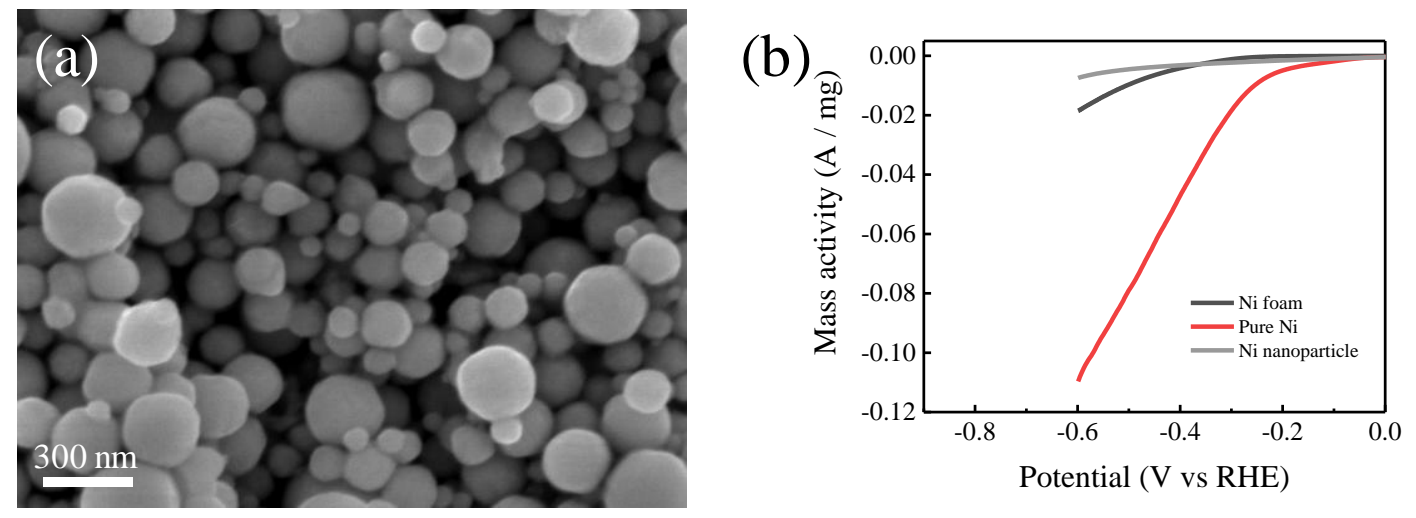

Figure S9. (a) SEM images of the commercial Ni nanoparticle. (b) LSV curves of the as-prepared 'pure Ni', commercial Ni foam and Ni nanoparticle. 

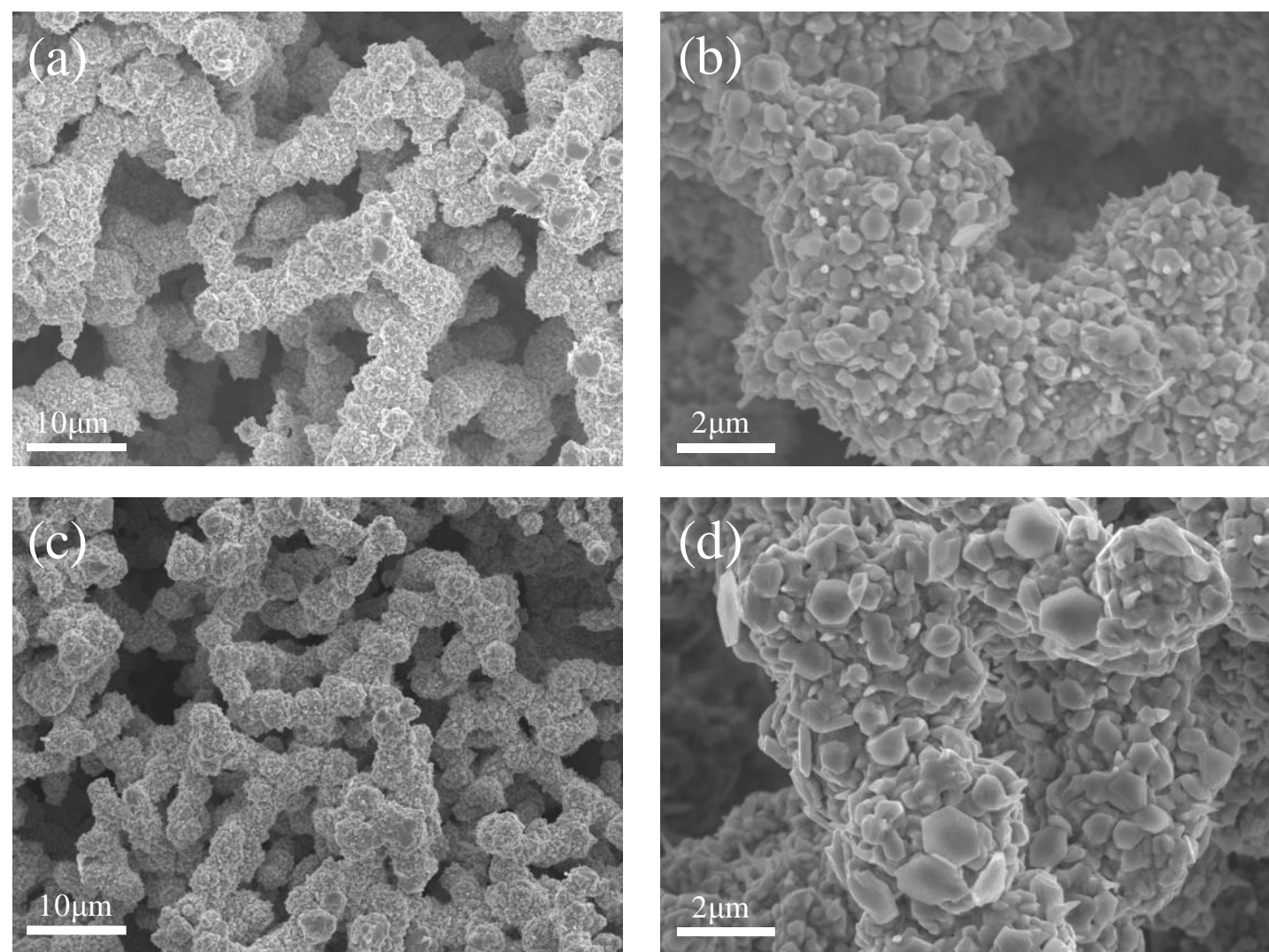

Figure S10. SEM images of the $\mathrm{Ni}_{0.95} \mathrm{Cu}_{0.05} \mathrm{DSS}(\mathrm{a})$, (b) after $10000 \mathrm{CV}$ circles and (c), (d) after $110 \mathrm{~h}$ at $1000 \mathrm{~mA} \mathrm{~cm}$. 

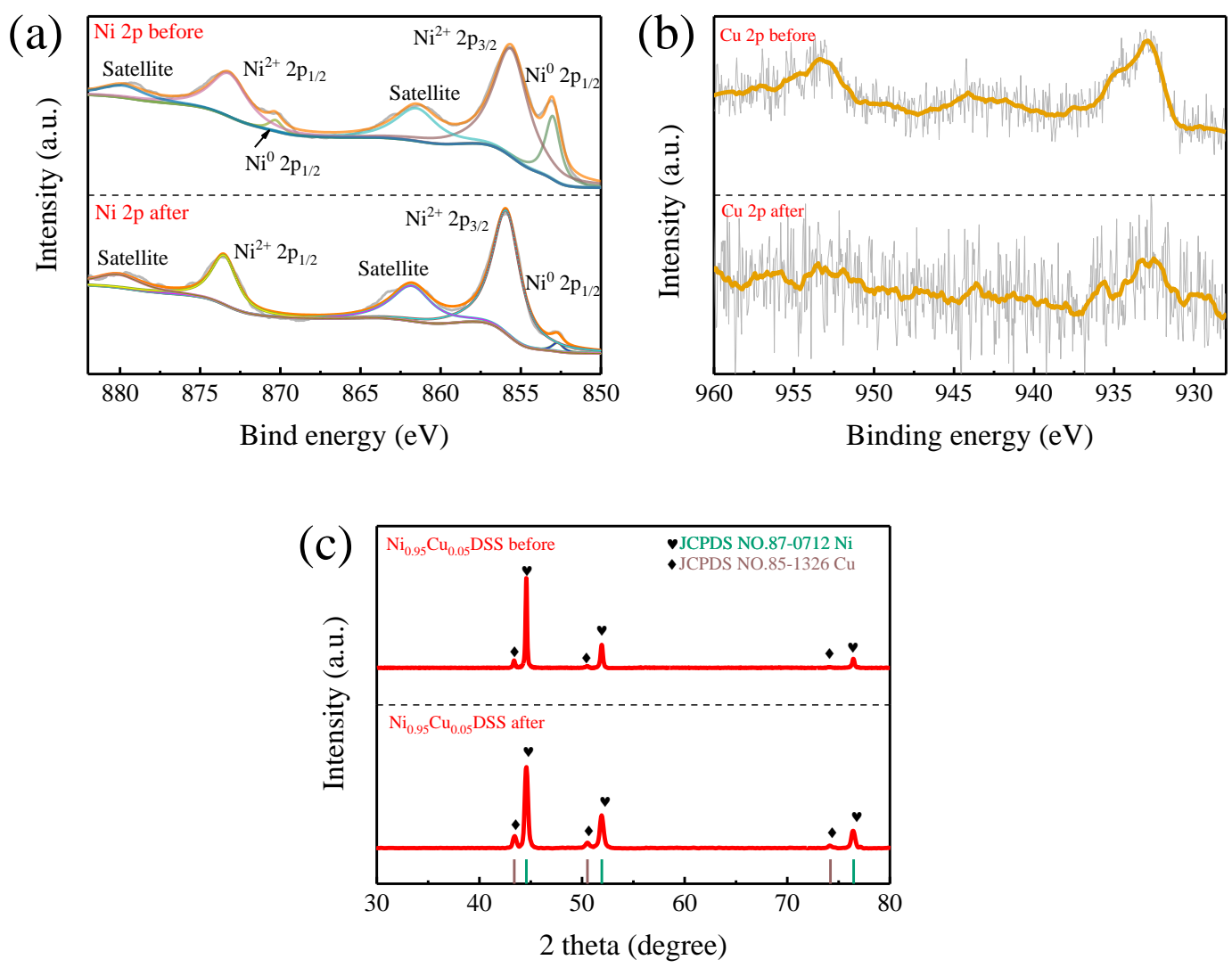

Figure S11. XPS spectra of (a) $\mathrm{Ni} 2 p$, (b) $\mathrm{Cu} 2 \mathrm{p}$ and (c) XRD patterns of $\mathrm{Ni}_{0.95} \mathrm{Cu}_{0.05} \mathrm{DSS}$, before and after $110 \mathrm{~h}$ continuous operation at $1000 \mathrm{~mA} \mathrm{~cm}{ }^{-2}$.

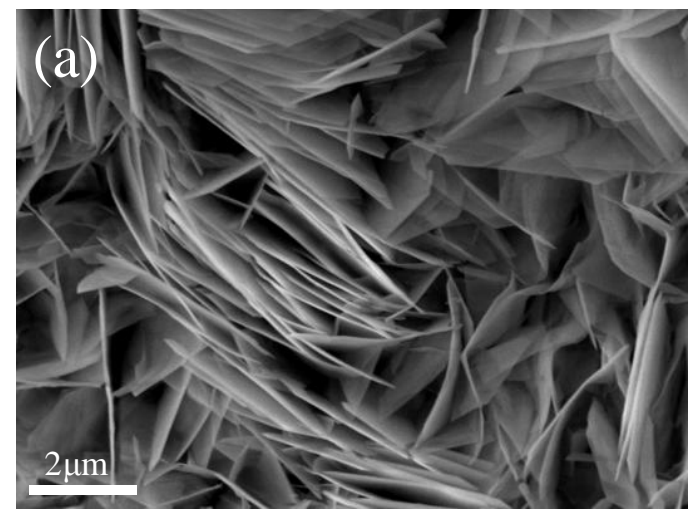

(b)

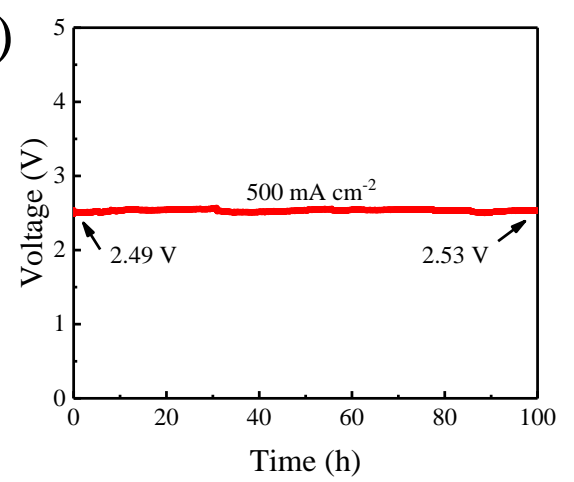

Figure S12. (a) SEM images of the Ni-Fe layered double hydroxide on Ni foam. (b)

Chronopotentiometry curves at $500 \mathrm{~mA} \mathrm{~cm}^{-2}$ using $\mathrm{NiFe} \mathrm{LDH} / \mathrm{NF}$ as the anode and $\mathrm{Ni}_{0.95} \mathrm{Cu}_{0.05} \mathrm{DSS}$ as the cathode without iR-compensation. 
Table S1. The content of $\mathrm{Ni}$ and $\mathrm{Cu}$ for $\mathrm{Ni}_{1-x} \mathrm{Cu}_{x} \mathrm{DSS}$ tested by ICP.

\begin{tabular}{|c|c|c|c|}
\hline & $\mathrm{Ni}_{0.97} \mathrm{Cu}_{0.03} \mathrm{DSS}$ & $\mathrm{Ni}_{0.95} \mathrm{Cu}_{0.05} \mathrm{DSS}$ & $\mathrm{Ni}_{0.9} \mathrm{Cu}_{0.1} \mathrm{DSS}$ \\
\hline $\mathrm{Ni}$ & $97.05 \%$ & $94.89 \%$ & $84.77 \%$ \\
\hline $\mathrm{Cu}$ & $2.82 \%$ & $4.94 \%$ & $11.08 \%$ \\
\hline
\end{tabular}

